\title{
Na construção de uma imagem, o passado se faz presente ${ }^{1}$
}

\author{
En la construcción de una imagen, el pasado se hace presente
}

In the construction of on image, the past is present

\author{
Juliana de Sá Françaª
}

\begin{abstract}
Resumo
Sabe-se que a língua não é neutra e que povos, lugares e, até mesmo, o status de uma língua estrangeira são constituídos no e pelo discurso. A partir da memória discursiva, que se apresenta permeada pela ideologia, os sujeitos significam o mundo por meio da linguagem ao mesmo tempo em que são interpretados por seus interlocutores. Assim, a abordagem de determinados temas selecionados pelos livros didáticos pode reforçar ou romper com sentidos que permeiam o imaginário dos sujeitos envolvidos no processo de ensino-aprendizagem. Tendo por base os fundamentos da Análise de Discurso de linha francesa, em especial a noção de memória, este trabalho objetiva refletir sobre efeitos de sentido relacionados à América Latina em uma unidade sobre diversidade cultural, presente em um livro didático de Língua Espanhola aprovado pelo Programa Nacional do Livro Didático. Para tanto, em um primeiro momento, apresenta-se um panorama sobre o ensino de línguas estrangeiras segundo a perspectiva discursiva, contemplando, também, o que preconizam documentos norteadores do ensino no Brasil em relação à diversidade cultural dos povos de fala hispana. Por fim, num gesto interpretativo, são apresentados efeitos de sentido sobre a América Latina a partir da materialidade discursiva analisada, observando se houve a superação de uma prática de ensino na Língua Espanhola que, durante muito tempo, pareceu mover-se em uma só direção: da Europa para os demais países. Entende-se que a língua não é um instrumento dócil e manejável, mas uma materialidade em que são tecidos discursos, sujeitos e memórias, o que possibilita questionamentos em torno dos discursos mobilizados no processo de ensino-aprendizagem.
\end{abstract}

Palavras-Chave: América Latina; Discurso; Diversidade Cultural; Memória.

\section{Resumen}

Se sabe que la lengua no es neutra y que pueblos, lugares e, incluso, el estatus de una lengua extranjera están constituidos en y por el discurso. A partir de la memoria discursiva, que se presenta permeada por la ideología, los sujetos significan el mundo por medio del lenguaje al mismo tiempo que son interpretados por sus interlocutores. Así, el abordaje de determinados temas seleccionados por los libros didácticos puede reforzar o romper con sentidos que permean el imaginario de los sujetos involucrados en el proceso de enseñanzaaprendizaje. Con base en los fundamentos del Análisis de Discurso de línea francesa, en especial la noción de memoria, este trabajo tiene como objetivo reflexionar sobre efectos de sentido relacionados a Latinoamérica en una unidad sobre diversidad cultural, presente en un libro didáctico de Lengua Española aprobado por el Programa Nacional del Libro Didáctico. En un primer momento, se presenta un panorama sobre la enseñanza de lenguas extranjeras de acuerdo con la perspectiva discursiva, teniendo presente, también, lo que preconizan documentos nacionales orientadores de la enseñanza en Brasil en lo que se refiere a la diversidad cultural de los pueblos de habla hispana. Por último, en un gesto interpretativo, se presentan efectos de sentido sobre Latinoamérica a partir de la materialidad discursiva analizada, observando si hubo la superación de una práctica de enseñanza en la Lengua Española que, durante mucho tiempo, pareció moverse en una sola dirección: de

\footnotetext{
1 Artigo apresentado no Simpósio Temático “A perspectiva intercultural em estudos sobre língua(s) de imigrantes e de fronteiras" durante o II Seminário Latino-Americano de Estudos em Cultura - SEMLACult em Foz do Iguaçu/PR, Brasil, 2018. O presente texto, com adaptações, faz parte da tese de Doutorado defendida pela autora.

${ }^{2}$ Doutora em Letras; Universidade Estadual do Oeste do Paraná - Unioeste; Marechal C. Rondon, Paraná, Brasil; julianadesa@gmail.com.
} 
Europa hacia los demás países. Se entiende que la lengua no es un instrumento dócil y manejable, sino una materialidad en que son tejidos discursos, sujetos y memorias, lo que posibilita cuestionamientos en torno a los discursos movilizados en el proceso de enseñanza-aprendizaje.

Palabras claves: Latinoamérica; Discurso; Diversidad Cultural; Memoria.

\begin{abstract}
It is known that language is not neutral and that people, places and even the status of a foreign language are building on and by discourse. From the discursive memory, which is permeated by ideology, subjects mean the world through language at the same time that they are interpreted by their interlocutors. Therefore, the approach of certain themes selected by textbooks can reinforce or break with the meanings that permeate the imaginary of the subjects involved in the teaching-learning process. Based on the foundations of French Discourse Analysis, in particular the memory notion, this paper aims to reflect on the meaning effects related to Latin America in a lesson about cultural diversity, presented in a textbook of Spanish Language approved by the National Textbook Program. For that, firstly there is an overview of foreign languages according to the discursive perspective, also contemplating what documents guide teaching in Brazil regarding the cultural diversity of Spanish-speaking people. Finally, in an interpretative way, effects of meaning on Latin America are presented from the discursive materiality analyzed, observing if there was an overcoming of a teaching practice in the Spanish language that, for a long time, seemed to move in just one direction: from Europe to other countries. It is understood that language is not a docile and manageable instrument, but a materiality in which discourses, subjects and memories are fabricated, which allows questions about the discourses involved in the teaching-learning process.
\end{abstract}

Keywords: Latin America; Discourse; Cultural diversity; Memory.

\title{
1. Introdução
}

Único país do continente americano a possuir a Língua Portuguesa como idioma oficial, o Brasil está rodeado por vizinhos, em sua maioria, hispano-falantes. Além de compartilhar de um mesmo passado, cujas raízes estão ancoradas na colonização, a posição geográfica brasileira, por si só, representaria razão suficiente para que o olhar do Brasil estivesse voltado para os demais países latino-americanos. Ocorre que, na prática, a aproximação e a valorização mútua entre os países da América Latina (doravante, AL) ainda está aquém daquilo que, por vezes, se almejou, inclusive por políticas integracionistas.

No que tange ao aspecto educacional, de acordo com Lessa (2013), há registros de que o estudante brasileiro sequer reconhece que é latino-americano. Como se o Brasil não constituísse política, social e historicamente esta realidade, ele traz em seu imaginário uma imagem homogeneizante, fragmentada e negativa sobre a AL.

Compreende-se que são os discursos que circulam pela sociedade que imprimem à América Latina status simbólico e material e que materiais didáticos gozam de certo poder sobre a construção do imaginário social. Diante dessas considerações e tomando a linguagem como materialidade linguística da(s) ideologias(s) que atravessa(m) os sujeitos, objetiva-se refletir à luz da Análise de Discurso de linha francesa (AD), a imagem discursivizada da AL em uma unidade da coleção didática de espanhol Cercanía Joven (CJ), aprovada pelo 
Programa Nacional do Livro Didático 2015 (PNLD) e adotada por escolas da rede pública de ensino do Oeste paranaense.

\section{Ensino de LE segundo a perspectiva discursiva}

Mais do que a apropriação de um novo código linguístico pelo qual o sujeito-falante encontra um instrumento para "se comunicar", o processo de ensino-aprendizagem de uma língua estrangeira deve ser encarado como um espaço de discursividade. Esse é o momento propício para que o sujeito reflita não só sobre temas estritos de metalinguagem, mas também sobre questões inerentes à própria língua, como a história, a condição de sujeito, as relações de força e a ideologia.

Serrani-Infante (2016) assinala que aprender uma LE compreende formulações que permitem a observação de representações da diversidade e que, no discurso, podem assumir “a forma de estereótipos, etnocentrismos, idealizações, exotismos, etc.”. Estas considerações se alinham ao que relatam as Orientações Curriculares Nacionais para o Ensino Médio (OCN, 2006) que apontam para um reducionismo, no imaginário brasileiro, da língua espanhola e dos povos/países hispano-falantes:

\footnotetext{
um reducionismo a que, ao longo da história, se viu afetada a nossa relação com a Língua Espanhola e com os povos que a falam. Estereótipos de todo tipo, sobre a língua e sua suposta facilidade para os brasileiros, sobre os hispanofalantes, mais de uma vez indiferenciados em imagens constituídas de fragmentos de diferentes setores do mundo hispânico, como se esse fosse uma só coisa, imagens permeadas de preconceitos que marcaram por muito tempo nossa relação com essa língua e essas culturas (BRASIL, 2006, p. 128).
}

O excerto destacado expõe duas faces da relação estabelecida no Brasil com a língua espanhola: A) a existência de uma ilusão de competência espontânea para o espanhol: como discutiu Celada (2002), o imaginário do brasileiro apresentava-se fortemente marcado, sobretudo antes da consolidação do Mercosul, por um pré-construído de o espanhol ser uma língua fácil, devido à sua semelhança com a estrutura da língua portuguesa, sendo, por isso, dispensável sua aprendizagem formal; B) a estigmatização do mundo hispânico: não se discutia sobre a diversidade, a história, a constituição ou a cultura dos povos hispano-falantes. À exceção da Espanha, os demais países hispano-falantes, quando não deixados totalmente à margem, eram abordados de forma despolitizada, periférica e/ou homogeneizante, como se gozassem das mesmas características e/ou sofressem com os mesmos problemas.

Em relação ao primeiro aspecto, pode-se dizer que o processo de globalização e as novas demandas por ele geradas, bem como a formação de blocos econômicos, a exemplo do Mercosul, têm como consequência uma nova tomada de posição relacionada ao espanhol. 
Conforme Celada (2002), a língua espanhola passa a ser vista como uma língua veicular, necessária para a circulação e para os negócios, fazendo com que o imaginário da competência espontânea seja, gradualmente, substituído pela visão de que, dado seu valor comercial, o espanhol merece e precisa ser estudado. Os novos sentidos instaurados contribuíram para o aumento da demanda dessa língua no Brasil e para a sua consequente oferta por distintas instituições de ensino.

O crescimento da demanda do espanhol veio acompanhado pela entrada do investimento estrangeiro no filão mercadológico aberto pela língua espanhola, principalmente de ações empreendidas pela Espanha para a exportação e comercialização de seu próprio idioma. A presença espanhola pôde ser sentida na abundante oferta de LDs e, também, no modelo linguístico a ser ensinado: a variedade peninsular. Se os LDs apresentam como referência a variedade europeia, o mesmo se pode inferir sobre a abordagem de temas culturais, que, não raro, incidem no estereótipo, conforme advertem as próprias OCN (2006).

Embora os documentos oficiais preconizem a superação do viés reducionista no ensino de espanhol e privilegiem a pluralidade linguística e cultural e o PNLD vise assegurar, dentre outros objetivos, que os LDs adotados pelas escolas brasileiras estejam isentos de preconceitos, caricaturas ou imagens estereotipadas, objetivo destas reflexões é observar como se apresenta a AL em uma unidade didática que discute a diversidade, uma vez que os sentidos não podem ser controlados.

\section{O passado se faz presente}

Reafirmando o compromisso, expresso em seu texto de apresentação, “de oportunizar o aluno a conhecer o mundo hispânico" e a refletir sobre temas que contribuam para uma formação crítica, $C J$ abre a coleção com uma unidade que objetiva destacar a pluralidade e a diversidade cultural das nações hispânicas. Por, supostamente, tratar-se do primeiro contato que os aprendizes terão com o ensino formal da língua espanhola, a temática e o escopo da unidade são pertinentes e estão em consonância com os documentos norteadores do ensino de línguas estrangeiras no Brasil.

Contudo, apesar de $C J$ buscar promover a imagem de que o seu discurso seria filiado à formação discursiva (FD) da diversidade, sua prática discursiva parece deslizar e se mover na direção contrária no que tange à $\mathrm{AL}$, percebendo-se, em determinados momentos, um viés estereotipado, como na seleção de algumas imagens, exaustivamente, repetidas em LDs e pela mídia, como uma que aparece inserida na unidade I do volume I, tomada aqui como alvo destas reflexões. 
Na materialidade imagética em questão, observa-se a tentativa de representação da diversidade dos povos latino-americanos, evocando figuras como a chola e o gaucho. Contudo, verifica-se que a representação é feita a partir de clichês, que, ao serem repetidos, convertem os sujeitos representados em estereótipos, criando a ilusão de serem os únicos representantes da cultura de seus países. Além disso, percebe-se que, embora essas sejam figuras recorrentes nos LDs de espanhol e, por extensão, em $C J$, o silêncio predomina quanto à relação desses símbolos com seus respectivos países. Dito de outra forma, sabe-se que o tango está para a Argentina, assim como as palenqueras estão para a Colômbia, mas não se fala do papel que desempenham - ou que já desempenharam - em seus contextos. Percebe-se, assim, uma abordagem da diversidade a partir de imagens engessadas, imunes ao equívoco e à heterogeneidade: há uma estagnação frente à alteridade. Lembra-se, conforme Ferreira (2011, p. 60), que, “assim como a língua resiste, a cultura também o faz e não se deixa capturar numa grade sem furos".

O sujeito do discurso ocupa várias posições, que demarcam sua heterogeneidade, fruto da multiplicidade de discursos que o constituem. Ao se afirmar que o discurso se constrói em relação ao discurso do outro, é preciso compreender que o outro não diz respeito a um interlocutor específico a quem o locutor se dirige. Nesse processo, estão envolvidos outros discursos historicamente constituídos e que emergem no discurso do sujeito. Diante desta perspectiva, a imagem relatada, que visa representar a diversidade latina, revela a tensão discursiva em que está imbricada CJ.

Dada sua constituição sócio-histórica, uma das principais características da AL é a convivência inter-racial e a miscigenação, oriunda do contato estabelecido entre diferentes povos, dentre os quais se destacam os indígenas, os negros e os brancos. É essa variedade étnica que $C J$ almeja representar em suas páginas, quando seu discurso se alinha à FD da diversidade. Apesar disso, constata-se que na imagem presente na unidade I, à exceção dos coloridos trajes típicos que os diferenciam, os sujeitos representados possuem os mesmos traços físicos e o mesmo tom de pele: são todos brancos. Revela-se, então, uma discrepância entre duas formações ideológicas distintas: uma, anterior, que tem no branco o ideal humano; e, outra, que celebra a diversidade em todas as suas formas, incluindo a racial.

Assim, CJ apaga as diferenças que deseja ressaltar ao reproduzir discursos que, historicamente, naturalizam a figura do branco. Nem sempre a diversidade racial foi algo discursivizado positivamente e orgulhosamente enfatizada: os registros históricos apontam que, durante muito tempo, considerou-se que a presença do elemento negro ou do indígena afastava a AL de uma aproximação com os ideais europeus. De acordo com Ribeiro (2017, p. 
21), traços raciais típicos do negro e do indígena continuam sendo um ponto de referência para preconceitos, pois “eles são a contraparte desprivilegiada dos euro-americanos”. Desta forma, perpetua-se uma ideologia que remonta ao período colonial e que resiste às regulações impostas pela atual ordem social, cultural e histórica e emerge em discursos que, supostamente, desejam confrontá-la: há pelo "viés inconsciente, uma série de estereótipos sociais que as pessoas possuem a respeito de outros grupos, um tipo de discriminação que tende a aparecer de forma automática, rápida, disfarçada e, em muitos casos, se pretende imperceptível” (ANTUNES; MODESTO, 2018, p. 345). A representação do branco está tão naturalizada e arraigada no imaginário social que $C J$ não se dá conta do desequilíbrio instaurado ao representar a diversidade latina tomando como referência o padrão branco.

Segundo as OCNs (2006, p. 133), o estudo de uma língua estrangeira deve "levar o estudante a ver-se e constituir-se como sujeito a partir do contato e da exposição ao outro, à diferença, ao reconhecimento da diversidade". Em consonância com elas, está o Edital do PNLD (2013, p. 47) que, entre seus critérios, expõe que se observará se a obra contempla textos que propiciem "o acesso à diversidade cultural, social, étnica, etária e de gênero manifestada na língua estrangeira, de modo a garantir a compreensão de que essa diversidade é inerente à constituição de uma língua e a das comunidades que nela se expressam". Enaltecendo a abordagem de um tema que versa sobre a diversidade, o LD abre um dos capítulos com a exposição em destaque da sequência discursiva (SD): "Turismo hispánico: ¡convivamos con las diferencias!”(COIMBRA; CHAVES; BARCIA, 2013, p. 27).

A primeira parte do enunciado - "turismo hispánico" - associada a "mundo hispánico", recorrente no discurso de $C J$, leva a inferir que o capítulo que se abre colocará em relevo pontos turísticos dos países aglutinados por aquela designação. Essa leitura aparenta ser coadunada pelo exposto na sequência (“convivamos con las diferencias"), que faz alusão a diferenças, evocando, novamente, o discurso da diversidade.

O verbo "conviver" abrange em sua acepção o reconhecimento do outro e a vivência entre partes distintas de forma pacífica e/ou em proximidade. "¡Convivamos con las diferencias!" é um convite para, via turismo hispânico, embarcar em uma viagem de observação, conhecimento e reflexão sobre diferentes localidades do "mundo hispánico" a partir daquilo que apresentam de singular.

Rompendo com a expectativa inicial, a imagem que acompanha a SD retrata, em destaque, referências consagradas do mundo europeu: a Torre Inclinada e a Fonte dos Querubins, em Pisa; localizados na Itália; a Torre Eiffel, em Paris (França); a Basílica de São 
Marcos e a Torre Veneziana, em Veneza (Itália); e o Coliseu, em Roma (Itália) - nenhum elemento da imagem remete ao "mundo hispânico".

Ao unir o enunciado verbal à materialidade não-verbal, $C J$ traz à tona outros discursos e cria um efeito de sentido de que é com as diferenças europeias que os hispânicos devem conviver. O "turismo hispânico" não está relacionado a pontos turísticos situados em localidades hispânicas, mas instiga que os povos pertencentes ao "mundo hispânico" se desloquem em direção àquilo que lhe é distinto, no caso, a determinadas localidades da Europa.

O tema AL - associado aqui ao adjetivo "hispânico", que também a englobaria parece ser tangenciado: a abordagem está mais situada no plano das ideias do que numa prática efetiva. Como afirma Pêcheux (1997), um dado discurso envia a outro e, assim, observa-se que o discurso de convivência com as diferenças expresso na materialidade verbal, quando associado à materialidade não-verbal, leva à ativação da memória da relação colonizador/colonizado. Neste caso, materialidade verbal, materialidade não-verbal e silêncio revelam vozes no discurso, inscritas em um posicionamento ideológico, segundo o qual os valores de determinadas sociedades devem servir de referência.

É significativo que, à exceção da Torre Eiffel, os demais locais em destaque na materialidade não-verbal situem-se na Itália, reconhecida como o principal centro do período Renascentista. Uma das características marcantes do Renascimento foi a promoção do retorno - (re)nascimento - da cultura clássica, sendo, por isso, considerado um movimento de propagação da cultura erudita do século XIV ao XVII, por toda a Europa. Em contraponto, no século XV, ao oeste do Atlântico, os bons servidores, aos olhos do colonizador europeu, eram, também, a marca da incivilidade, pois lhes faltava uma série de atributos necessários para atingir o ideal de civilização europeu. De acordo com Mariani (2004), a colonização engendrada pelas metrópoles se baseava na ideologia do déficit, o que legitimava a dominação imposta. Criou-se, deste modo, uma polarização entre a Europa civilizada, referência em cultura e modelo a ser seguido, e a AL, bárbara, selvagem e carente de erudição.

Neste sentido, parece estar sedimentado no imaginário latino-americano que ele precisa espelhar-se nos padrões europeus, “cujas características específicas não são mais, há séculos, colocadas em questão, pois já estão definitivamente fixadas" (ORLANDI, 2008, p. 54), ou em localidades que desfrutam de prestígio na era da globalização, como os Estados Unidos. Percebe-se como, atualmente, ainda soa sedutora e goza de prestígio a ideia de uma viagem, um curso, um trabalho no exterior ou, ainda, o orgulho com que se relata que um 
parente, um amigo ou um conhecido mora fora do país (mais especificamente na Europa ou na América do Norte).

A SD e a materialidade não-linguística a ela associada revelam a interpelação ideológica sofrida por $C J$, que se materializa na repetição de um discurso segundo o qual a AL, quando posta em relação com outros núcleos de poder (econômico e cultural), deve buscar nesses referentes o preenchimento das lacunas relacionadas àquilo que, supostamente, falta-lhe. Há o imaginário de que é o no espaço do outro que estão a cultura, a educação, a riqueza, os hábitos, a beleza e a perfeição que se almeja conquistar.

Assim, na emergência da "atualidade" do discurso da diversidade, sempre retomado pela esfera educacional, $C J$, interpelada pela ideologia, acaba por acionar via interdiscurso a memória de um outro discurso: aquele cujas raízes estão fincadas no processo de colonização latino-americana e cujos sentidos fogem àqueles que se pretende enaltecer.

\section{Considerações}

As reflexões aqui realizadas apontaram para um discurso que, visando "celebrar" a diversidade do "mundo hispânico", dá lugar ao atravessamento de vozes que incidem no campo do já-dito. Percebe-se que há a tentativa de inclusão de elementos latino-americanos em $C J$ entretanto sua sustentação é feita a partir do lugar comum, implicando uma abordagem superficial, que pouco difere de práticas discursivas que marcaram não só o ensino de língua espanhola, mas o imaginário brasileiro sobre os países que integram a AL.

Entende-se que é no e pelo discurso que sentidos são cristalizados e, na mesma medida, podem ser desconstruídos; por isso acredita-se que a reflexão acerca da discursivização da AL em materiais didáticos adotados por escolas da rede pública de ensino, pode contribuir para discussões acerca da conscientização e do respeito com as diferenças culturais e linguísticas, tal qual preveem os documentos oficiais de ensino de línguas no Brasil.

Neste sentido, o olhar sobre os LDs pode oferecer contribuições a campos diversos do saber: aos estudos da linguagem, devido ao foco no discurso; aos estudos sobre ensino, devido à escolha do corpus; e à história, sociologia e áreas relacionadas, por tratar de um tema de interesse também dessas disciplinas. A reflexão pode colaborar, também, com discussões empreendidas, sobretudo nos cursos de Licenciatura, para: a) reavaliar as práticas discursivas sobre o ensino de línguas; b) analisar criticamente materiais que baseiam as práticas de ensino nas salas de aula; c) refletir acerca das práticas ideológicas que atravessam materiais 
utilizados no ambiente escolar, provocando questionamentos sobre os discursos socialmente cristalizados.

\section{Referências}

ANTUNES, Viviane Conceição; MODESTO, Wallace Oliveira. Herança africana nos livros didáticos de espanhol: ainda em busca da representatividade. IN: BARROS, Cristiano Silva de; COSTA, Elzimar Goettenauer; FREITAS, Luciana Maria Almeida. O livro didático de espanhol na escola brasileira. Campinas: Pontes Editores, 2018.

BRASIL. Orientações Curriculares Nacionais para o Ensino Médio. Brasília: MEC, 2006.

Edital de Convocação 01/2013 - Edital de convocação para o processo de inscrição e avaliação de obras didáticas para o programa nacional do livro didático PNLD 2015. Brasília, 2013.

Guia de livros didáticos PNLD 2015: língua estrangeira moderna. Brasília: Ministério da Educação, Secretaria de Educação Básica, 2014.

CELADA, María Teresa. O espanhol para o brasileiro: uma língua singularmente estrangeira. 2002. [s.n.] Tese (Doutorado). Campinas: Universidade Estadual de Campinas, Instituto de Estudos da Linguagem, 2002.

COIMBRA, Ludmila; CHAVES, Luiza Santana; BARCIA, Pedro. Cercanía Joven: espanhol, $1^{\circ}$ ano. São Paulo: Edições SM, 2013.

CORACINI, Maria José Rodrigues Faria. Pobreza e marginalidade em livro didático de francês como língua estrangeira: entre o poder e a discriminação. In: CORACINI, Maria José Rodrigues Faria; CAVALLARI, Juliana Santana. (Orgs.). (Des)construindo verdade(s) no/pelo material didático: discurso, identidade, ensino. Campinas: Pontes, 2016.

CORACINI, Maria José Rodrigues Faria; CAVALLARI, Juliana Santana. Prefácio. In: CORACINI, Maria José Rodrigues Faria; CAVALLARI, Juliana Santana. (Orgs.). (Des)construindo verdade(s) no/pelo material didático: discurso, identidade, ensino. Campinas: Pontes, 2016.

FERREIRA, Maria Cristina Leandro. O lugar do social e da cultura numa dimensão discursiva. IN: IN: INDURSKY, Freda; MITTMAN, Solange; FERREIRA, Maria Cristina Leandro (orgs.). Memória e história na/da Análise do Discurso. Campinas: Mercado de Letras, 2011.

LESSA, Giane da Silva Mariano. Memórias e identidades latino-americanas invisíveis e silenciadas no ensino-aprendizagem de espanhol e o papel político do professor. IN: ZOLIN-VESZ, Fernando (Org.). A (in)visibilidade da América Latina no ensino de Espanhol. Campinas: Pontes Editores, 2013.

MARIANI, Bethânia. Colonização linguística. Campinas: Pontes, 2004.

NOGUEIRA, Alessandra Sartori. Efeitos da memória discursiva na estereotipagem do povo brasileiro quando comparado ao estadunidense e ao inglês. IN: BERTOLDO, Ernesto 
Sergio; MUSSALIM, Fernanda (orgs.). Análise do discurso: aspectos da discursividade no ensino. Goiânia: Trilhas Urbanas, 2006.

ORLANDI, Eni. Terra à vista: discurso de confronto entre o Velho e o Novo Mundo. Campinas: Editora da Unicamp, 2008.

PÊCHEUX, Michel. A Análise de Discurso: três épocas (1983). IN: GADET, F.; HAK, T. Por uma análise automática do discurso: uma introdução à obra de Michel Pêcheux. Campinas: Editora da Unicamp, 1997.

REVUZ, Christiane. A língua estrangeira entre o desejo de um outro lugar e o risco do exílio. IN: SIGNORINI, Inês (org.). Lingua(gem) e identidade: elementos para uma discussão no campo aplicado. São Paulo: Mercado de Letras, 2016.

RIBEIRO, Darcy. América Latina: a pátria grande. São Paulo: Global, 2017.

SERRANI-INFANTE, Silvana. Identidade e segundas línguas: as identificações no discurso. IN: SIGNORINI, Inês (org.). Lingua (gem) e identidade: elementos para uma discussão no campo aplicado. São Paulo: Mercado de Letras, 2016.

SOUZA, Deusa Maria. Gestos de censura. IN: CORACINI, Maria José Rodrigues Faria (org.). Interpretação, autoria e legitimação do livro didático. Campinas: Pontes, 1999. 